\title{
Erratum to: Universal Logic and Aristotelian Logic: Formality and Essence of Logic
}

Julie Brumberg-Chaumont

\section{Erratum to: Log. Univers. \\ DOI 10.1007/s11787-015-0123-y}

Unfortunately, the fifth sentence in the first paragraph of the "Introduction" section was incorrectly published. The correct sentence should read as:

Some medieval authors, such as William of Ockham in the fourteenth century, or Avicenna, in the eleventh century, did bring important logical novelties one could characterize as "extra-Aristotelian" or even "non-Aristotelian".

Julie Brumberg-Chaumont

CNRS

Paris, France

e-mail: brumberg@vjf.cnrs.fr

The online version of the original article can be found under doi:10.1007/s11787-015-0123-y. 